\title{
Freezing experiments on unsaturated sand, loam and silt loam
}

\author{
Kunio WATANABE, ${ }^{1}$ Tetsuya KITO, ${ }^{1}$ Tomomi WAKE, ${ }^{1}$ Masaru SAKAI ${ }^{2}$ \\ ${ }^{1}$ Graduate School of Bioresources, Mie University, 1577 Kurima-Machiya, Tsu 514-8507, Japan \\ E-mail: kunio@bio.mie-u.ac.jp \\ ${ }^{2}$ Department of Plants, Soils, and Climate, Utah State University, 4820 Old Main Hill, Logan, UT 84322-4820, USA
}

\begin{abstract}
Estimating soil-water flow during ground freezing is important for understanding factors affecting spring farming, soil microbial activity below the frozen soil, and permafrost thawing behavior. In this study, we performed a column freezing experiment using three different unsaturated soils (sand, loam and silt loam) to obtain a detailed dataset of temperature, water-content and pressure-head change under freezing conditions. The liquid water content and pressure head in the three soils decreased with decreasing temperature. Three soil temperature stages were found: unfrozen, stagnating near $0^{\circ} \mathrm{C}$ and frozen. The temperature and duration of the stagnation stage differed among the soil types. The changes in liquid water content and pressure head during the freezing process were highly dependent on the soilwater retention curve. Water flowed through the frozen area in silt loam and sand, but no water flux was observed in the frozen loam. The freezing soil columns tended to contain more liquid water than estimated from retention curves measured at room temperature, especially at the early stage of freezing.
\end{abstract}

\section{INTRODUCTION}

The amount of unfrozen water in frozen soil decreases with decreasing soil temperature. The pressure of unfrozen water in frozen soil, which can be estimated from the temperature of the frozen soil, is lower than that of water in non-frozen soil, inducing soil-water flow from unfrozen subsoil to frozen top soil during ground freezing. Temperature changes associated with recent changes in climate have altered the frost-induced soil-water redistribution in the vadose zone and the spatial variation of unfrozen water and ice profiles of surface soils in cold regions. These changes in the soil-water environment affect not only human activities such as farm operations (Baker and Spaans, 1997) and farmland soil erosion (Singh and others, 2009), but also soil microbial activity below the frozen soil (Watanabe and Ito, 2008), evapotranspiration from cold regions, and permafrost thawing behavior (Lopez, 2007), which have feedback effects on the changing climate itself.

Water flow in unsaturated soil during freezing can be calculated by solving Richards' equation and the heat transfer equation including the phase transition of water (e.g. Hansson and others 2004). To solve these transfer equations, it is fundamentally important to appropriately express hydraulic properties such as the soil-water retention curve (relationship between pressure head, $h$, and water content, $\theta$ ) and unsaturated hydraulic conductivity of frozen soil. In particular, the hydraulic properties near the freezing front have a substantial impact on water flow from unfrozen to frozen soil. However, direct measurement of the hydraulic properties of frozen soil is difficult. Although several freezing experiments using unsaturated soils have been performed (e.g. Fukuda and others, 1980; Jame and Norum, 1980; Mizoguchi and others, 1986), continuous measurements of temperature, water content and pressure head near the freezing front are still lacking because of the difficulty in measuring the amount and pressure of unfrozen water. Thus, the hydraulic properties near the freezing front have not been adequately investigated. Furthermore, water flow in unsaturated soil depends on soil type because each type has characteristic hydraulic properties. However, few examples are available comparing soil-water profiles in frozen soils among soil types with similar initial and boundary conditions. The collection of a detailed dataset of temperature, water content and pressure head for different soil types under freezing conditions would provide a good basis for future studies of the effects of climate change on the water dynamics of freezing soil.

In soil-freezing models, the amount of unfrozen water in the frozen soil at a given temperature is sometimes assumed to be the same as the amount of water derived from the soil-water retention curve for non-frozen soil and the pressure head estimated from the temperature and the Clausius-Clapeyron equation, assuming the ice in frozen soil pores has the same geometry as air in unsaturated nonfrozen soil (Williams, 1964; Miller, 1973). This assumption has been verified in several frozen soils under temperatureequilibrium conditions (Koopmans and Miller, 1966; Black and Tice, 1989; Spaans and Baker, 1996). However, in soils in the middle of the freezing process, soil-water flow through the freezing front and the speed of temperature decline near the freezing front change with time. Thus, more discussion is needed on the relationship between unfrozen water content and the pressure head in soils undergoing freezing.

Recently, several calibration models for time domain reflectometry (TDR) have been proposed that include the dielectric permittivity of ice and reduction of the permittivity of unfrozen water by surface forces (Bittelli and others, 2004; Watanabe and Wake, 2009), resulting in a massive improvement in the measurement of unfrozen water in frozen soils (Stähli and Stadler, 1997; Watanabe and Wake, 2008). Here we performed laboratory freezing experiments using three different unsaturated soils (sand, loam and silt loam) and continuously measured temperature, unfrozen water, and pressure head using tensiometers and TDR. We then estimated the pressure head of unfrozen water in frozen soil based on temperature and the Clausius-Clapeyron equation and investigated the relationship between unfrozen water content and the pressure head near the freezing front for the three soils during the freezing process. 

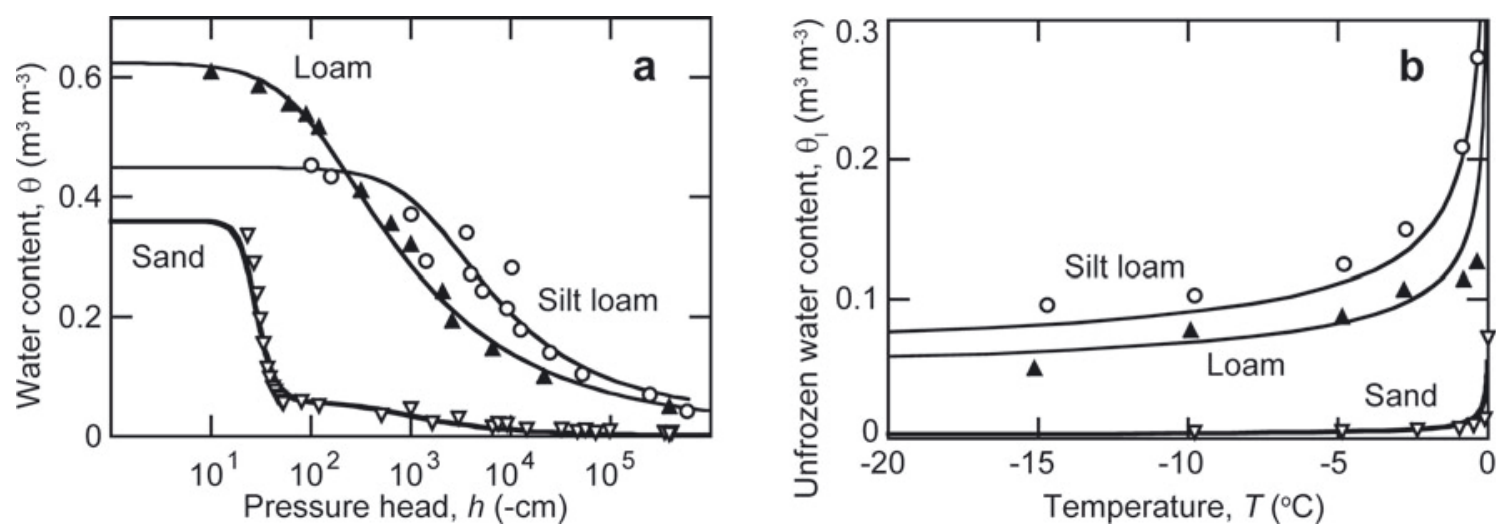

Fig. 1. (a) Soil-water retention curve measured by hanging water method, pressure plate method and dew-point water potential meter at $25^{\circ} \mathrm{C}$; (b) soil-water freezing curve measured by nuclear magnetic resonance. The solid curves are fitting curves by Equation (1).

\section{MATERIALS AND METHODS}

The samples used here were Tottori dune sand (sand), Fujinomori subsoil (silt loam) and Tokachi topsoil (loam) from Japan. The sand was first washed in deionized water and the silt loam was passed through a $2 \mathrm{~mm}$ screen. We used raw plowed soil for the loam. Figure 1a shows the soilwater retention curves (relationship between pressure head, $h$, and water content, $\theta$ ) for the soils measured using the hanging water method $(-160<h<-10 \mathrm{~cm})$, pressure plate method $\left(-10^{4}<h<-150 \mathrm{~cm}\right)$ and dew-point water potential meter $\left(h<-10^{3} \mathrm{~cm}\right)$ at $25^{\circ} \mathrm{C}$. The curves were fitted by

$$
\frac{\theta-\theta_{\mathrm{r}}}{\theta_{\mathrm{s}}-\theta_{\mathrm{r}}}=\left(1-w_{2}\right)\left[1+\left(\alpha_{1} h\right)^{n_{1}}\right]^{-m_{1}}+w_{2}\left[1+\left(\alpha_{2} h\right)^{n_{2}}\right]^{-m_{2}}
$$

(Van Genuchten, 1980; Durner, 1994), where $\theta$ is the volumetric water content, $\theta_{\mathrm{r}}$ and $\theta_{\mathrm{s}}$ are the residual and saturated water contents, respectively, $w_{2}$ is a weighting parameter, and $\alpha, n$ and $m=1-(1 / n)$ are parameters for determining the shape of the retention curve. Table 1 lists the optimized parameters of Equation (1) for the three soils. Figure $1 \mathrm{~b}$ shows the soil freezing curve (relationship between temperature, $T$, and unfrozen water content, $\left.\theta_{1}\right)$ measured using pulsed nuclear magnetic resonance (NMR) at temperature equilibrium. Most of the water in the sand froze at $-1{ }^{\circ} \mathrm{C}$, while the silt loam and loam contained $\sim 0.1 \mathrm{~m}^{3} \mathrm{~m}^{-3}$ of unfrozen (liquid) water, even at $-20^{\circ} \mathrm{C}$. The solid curve in Figure $1 \mathrm{~b}$ is the soil retention curve (Fig. 1a), in which $T$ was converted from the pressure head, $h$, using the Clausius-Clapeyron equation with assumptions that the pressure of pore ice is equal to atmospheric pressure and that the solute effect is negligible. The Clausius-Clapeyron equation can be written as

$$
h=\frac{v L_{\mathrm{f}}}{\rho_{\mathrm{b}} g} \ln \frac{T}{T_{\mathrm{m}}},
$$

where $v$ is the specific volume, $T_{\mathrm{m}}$ is the melting point of bulk water, $L_{f}$ is the latent heat of fusion, and $g$ is the acceleration of gravity. The freezing curves for all soils were in agreement with the water retention curves in the lowpressure ranges $\left(-10^{5}<h<-10^{3} \mathrm{~cm}\right)$.

The sand and the silt loam were mixed with distilled, deionized water and packed into acrylic sample columns with an internal diameter of $7.8 \mathrm{~cm}$ and a height of $35 \mathrm{~cm}$. The loam was packed into a column at the same bulk density and water content as found in the field. Table 2 lists the density and water content of the three soils and also shows the equivalent pressure head for the soils obtained from the retention curves (Fig. 1a). Two water contents were prepared for silt loam: one was the same water content as the loam (silt loam 1: $\theta=0.40$ ), and the other had the same equivalent pressure as the sand (silt loam 2: $h=-35 \mathrm{~cm}$ ). A schematic of the freezing apparatus is shown in Figure 2. The column was set between control units that regulated top and bottom temperature. Thirty-four copper-constantan thermocouples $(1 \mathrm{~cm}$ intervals), seven time-domain reflectometry (TDR) probes and seven tensiometers (5 $\mathrm{cm}$ intervals) were inserted horizontally into the soil columns, and the side-walls of the columns were insulated with $1 \mathrm{~cm}$ thick rubber sheet and glass wool. The relative permittivity of frozen soil is affected by not only liquid water content but also ice and absorbed water contents. Therefore, the TDR was first calibrated for measuring unfrozen water content by comparison with the pulsed NMR measurement (Watanabe and Wake, 2009). The apparatus was then settled at an ambient temperature of $4{ }^{\circ} \mathrm{C}$ for 24 hours to establish the initial water and temperature profiles and then frozen from the upper end by controlling the temperature at both ends of the column, $T_{\mathrm{L}}$ and $T_{\mathrm{H}}$ (Table 2). No water flux was allowed from either end. During the experiment the profiles of temperature, liquid water content and pressure head were monitored using thermo-

\begin{tabular}{|c|c|c|c|c|c|c|c|}
\hline & $\theta_{\mathrm{s}}$ & $\theta_{\mathrm{r}}$ & $\alpha_{1}$ & $n_{1}$ & $w_{2}$ & $a_{2}$ & $n_{2}$ \\
\hline Sand & 0.36 & 0.0016 & 0.0371 & 5.16 & 0.158 & 0.0022 & 1.57 \\
\hline Loam & 0.625 & 0.019 & 0.0101 & 1.35 & 0 & - & - \\
\hline Silt loam & 0.46 & 0.036 & 0.000667 & 1.46 & 0 & - & - \\
\hline
\end{tabular}

Table 1. Parameters for Equation (1) 
Table 2. Initial and experimental conditions for three soils. $\rho_{\mathrm{b}}$ is bulk density $\left(\mathrm{g} \mathrm{cm}^{-3}\right), \theta_{\mathrm{p}}$ and $h_{\mathrm{p}}$ are water content and pressure head when packed into the column, and $T_{\mathrm{H}}$ and $T_{\mathrm{L}}$ are given temperature at top and bottom ends $\left({ }^{\circ} \mathrm{C}\right)$

\begin{tabular}{lccccc}
\hline & $\rho_{\mathrm{b}}$ & $\theta_{\mathrm{P}}$ & $h_{\mathrm{P}}$ & $T_{\mathrm{H}}$ & $T_{\mathrm{L}}$ \\
& & & & & \\
\hline Sand & 1.45 & 0.15 & -35 & 2 & -8 \\
Loam & 0.95 & 0.40 & -315 & 2 & -8 \\
Silt loam 1 & 1.18 & 0.40 & -800 & 2 & -8 \\
Silt loam 2 & 1.18 & 0.44 & -35 & 2 & -10 \\
& & & & & \\
\hline
\end{tabular}

couples, TDRs and tensiometers. The pressure head was measurable up to about $h=-850 \mathrm{~cm}$ by tensiometer. For subzero temperatures, the pressure head could be estimated using temperature and Equation $(2)(\sim h<-800 \mathrm{~cm})$. At the same depth, the temperature difference between the column center and the vicinity of the column wall was $<0.1^{\circ} \mathrm{C}$. For each initial condition, five similarly prepared columns were frozen with different durations of freezing, and the total water content was measured by sectioning a column at $2.5 \mathrm{~cm}$ intervals when it froze and after 6, 12, 24 and 48 hours. The thermocouple and TDR readings confirmed that all columns had the same temperature and water profiles during freezing under the same experimental conditions. In all experiments, no ice lens or frost heave was observed.

\section{RESULTS AND DISCUSSION}

\section{Change in liquid water content and pressure in freezing soils}

Figure 3 shows the changes in temperature, liquid water content (total water content at temperatures above $0^{\circ} \mathrm{C}$ and unfrozen water content at temperatures below $0^{\circ} \mathrm{C}$ ) and pressure head at each depth of the three soils during the freezing process. In the case of silt loam, the difference in temperature boundary condition $\left(T_{\mathrm{L}}=-8\right.$ or $\left.-10^{\circ} \mathrm{C}\right)$ led to a $2 \mathrm{~cm}$ difference in frost penetration depth over 48 hours and a similar decreasing trend for temperature, water content and pressure head; hence, only the results for higher water conditions (silt loam 2) are shown in Figure 3. When both ends of the columns were set at different temperatures $\left(T_{\mathrm{L}}\right.$ and $T_{\mathrm{H}}$ ), the temperature of the soil column decreased with depth (Fig. 3a-c). The freezing front advanced faster in the upper part of the column and slowed over time. The temperature change was divided into three stages: the unfrozen stage, the temperature-stagnating stage near the bulk melting temperature due to latent heat release, and the frozen stage in which the temperature decreased below the melting temperature (see indicators on right axis of Fig. 3). The stagnating stage lengthened in the lower part of the column (slower cooling rate) and barely appeared in the sand. The stagnating temperatures were 0 to $-0.03^{\circ} \mathrm{C}$ for the sand, 0 to $-0.3^{\circ} \mathrm{C}$ for the loam and 0 to $-0.6^{\circ} \mathrm{C}$ for the silt loam. We needed $>48$ hours to produce a steady temperature profile for any soil under the experimental conditions.

In the unfrozen stage, the liquid water content in each soil decreased gradually with time (Fig. $3 \mathrm{~d}-\mathrm{f}$ ) due to water flow to the freezing front. In the stagnating stage, the liquid (unfrozen) water content decreased with only slight temperature changes, while the water content in the frozen stage

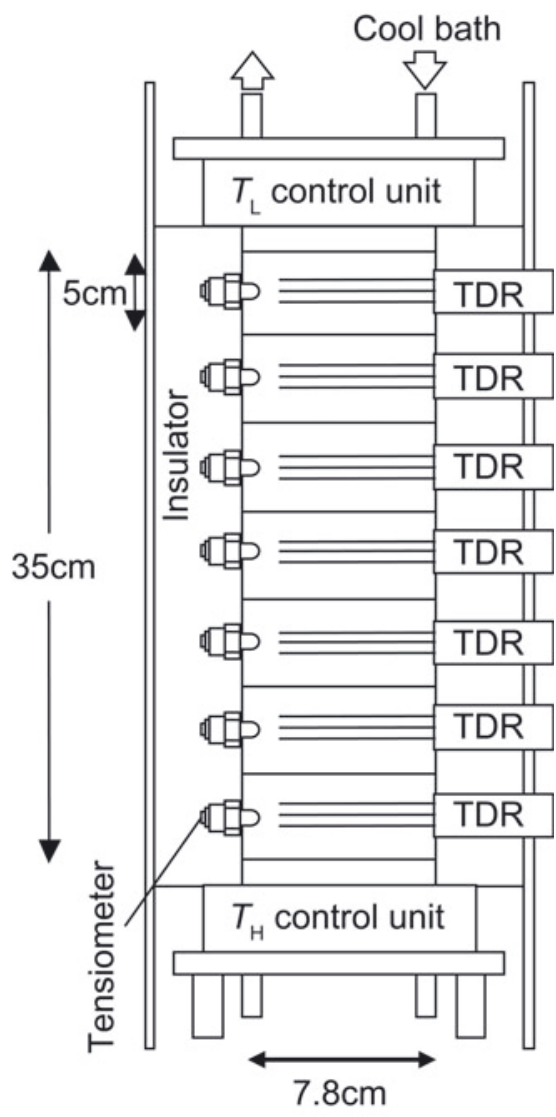

Fig. 2. Schematic illustration of experimental apparatus.

decreased with temperature. The main reason for the change in water content in the stagnating and frozen stages was the phase transition to ice, but it also would include the redistribution of unfrozen water in soil that had already frozen.

In the case of sand, the initial water content, $\theta_{0}$, and pressure head, $h_{0}$, varied with depth due to gravity (Fig. $3 d$ and g). For the unfrozen stage, the water content and pressure did not change much in areas shallower than $22.5 \mathrm{~cm}$, where the initial conditions were relatively dry $\left(\theta_{0}<0.15 \mathrm{~m}^{3} \mathrm{~m}^{-3}\right)$, while the water content decreased gradually in areas deeper than $22.5 \mathrm{~cm}\left(\theta_{0}>0.15 \mathrm{~m}^{3} \mathrm{~m}^{-3}\right)$. Sand holds little water in the low-pressure range, and the water content hardly changes at values of pressure head $\mathrm{h}<-50 \mathrm{~cm}$ (Fig. 1a). Hence, when pressure head decreased at the freezing front, water would be supplied from deeper layers $\left(h_{0}>-35 \mathrm{~cm}\right)$, where water content easily changes with small pressure differences (Fig. 1a), instead of from shallower layers $\left(h_{0}<-35 \mathrm{~cm}\right)$. For the frozen stage, the water content decreased steeply with temperature and became constant when temperature reached quasi-equilibrium (Fig. $3 a$ and d). This corresponded to the soil freezing curve shown in Figure $1 \mathrm{~b}$. During this stage, the pressure decreased suddenly in the temperature range $-0.06<T<0^{\circ} \mathrm{C}$, and could not be measured with the tensiometer (Fig. $3 g$ ).

In the case of loam, the initial water content and pressure head were roughly constant throughout the column, at $\theta_{0} \approx 0.4 \mathrm{~m}^{3} \mathrm{~m}^{-3}$ and $h_{0} \approx-300 \mathrm{~cm}$, respectively (Fig. 3e and h). In contrast to the sand, the water content and pressure at all depths decreased gradually in the unfrozen stage. The frost penetration depth at 48 hours was $\sim 18 \mathrm{~cm}$. When the soil reached the stagnating stage $\left(T=-0.01^{\circ} \mathrm{C}\right)$, the water content was $\theta=0.39-0.37 \mathrm{~m}^{3} \mathrm{~m}^{-3}$ and the pressure head was 

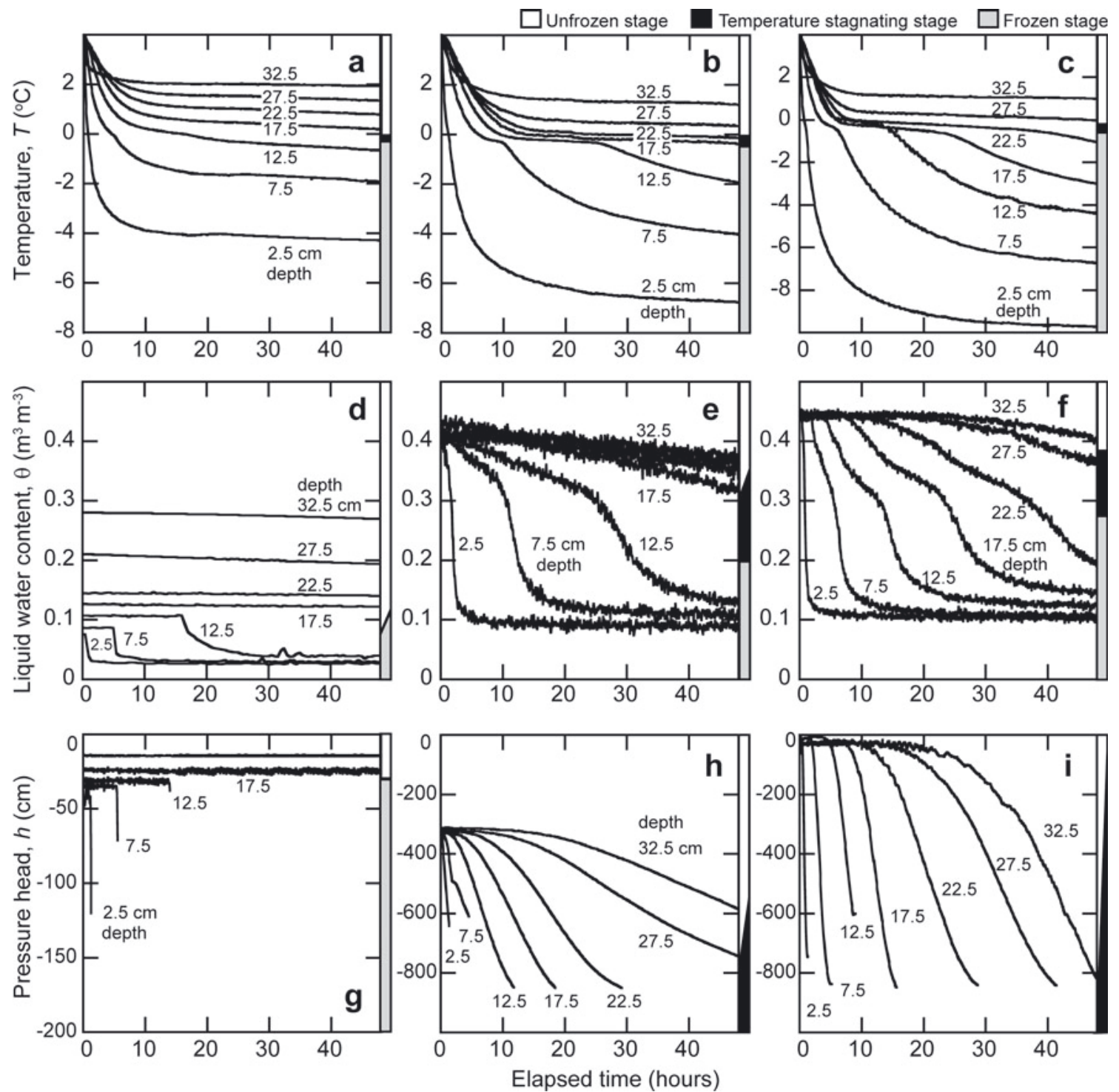

Fig. 3. Changes in temperature $(a-c)$, liquid water content $(d-f)$ and pressure head $(g-i)$ for three soil columns during the freezing process: $(\mathrm{a}, \mathrm{d}, \mathrm{g})$ sand, $(\mathrm{b}, \mathrm{e}, \mathrm{h})$ loam and $(\mathrm{c}, \mathrm{f}, \mathrm{i})$ silt loam. The indicator on the right axis illustrates three freezing temperature stages: unfrozen, stagnating near $0^{\circ} \mathrm{C}$ and frozen.

$-761,-688$ and $-795 \mathrm{~cm}$ at depths of $7.5,12.5$ and $17.5 \mathrm{~cm}$, respectively. At these depths, liquid (unfrozen) water decreased to $0.25 \mathrm{~m}^{3} \mathrm{~m}^{-3}$ during the stagnating stage and decreased continuously to $0.1 \mathrm{~m}^{3} \mathrm{~m}^{-3}$ during the frozen stage. The pressure head decreased smoothly from the unfrozen to the stagnating stages and became unmeasurable at about $-900 \mathrm{~cm}\left(T=-0.2\right.$ to $\left.-0.24^{\circ} \mathrm{C}\right)$. According to Figure $1 \mathrm{~b}$ and Equation (2), the water content of the loam at the end of the stagnating stage $\left(T=-0.3^{\circ} \mathrm{C}\right)$ should be $0.19 \mathrm{~m}^{3} \mathrm{~m}^{-3}$, which is lower than the water content seen in the column experiment. Ice may not have been able to form an equilibrium amount at the beginning of freezing, and the soil had more liquid water than expected based on the freezing curve obtained at equilibrium state.

In the case of silt loam, the water content and pressure head at depths less than $27.5 \mathrm{~cm}$ did not change during the unfrozen stage, and decreased suddenly near the start of the stagnating stage (Fig. $3 \mathrm{f}$ and i). When the soil reached the stagnating stage $\left(T=-0.01^{\circ} \mathrm{C}\right)$, the water content and pressure head were $\theta=0.37 \mathrm{~m}^{3} \mathrm{~m}^{-3}$ and $h=-540,-413$ and $-904 \mathrm{~cm}$ at $7.5,12.5$ and $27.5 \mathrm{~cm}$ depth, respectively, and $\theta=0.44 \mathrm{~m}^{3} \mathrm{~m}^{-3}$ and $h=-22 \mathrm{~cm}$ at 17.5 and $22.5 \mathrm{~cm}$ depth. The decreasing rate of decline of liquid water content in the silt loam changed during the stagnating stage and was slower than those in sand and loam (Fig. 3f). These differences in rate of change of liquid water content and pressure by soil type may be explained by the water retention curves for the various soil types: silt loam holds water near saturation until it starts to freeze $(h \approx-1000 \mathrm{~cm}$, equivalent to $T \approx-0.1^{\circ} \mathrm{C}$ by Equation (2)); sand, in contrast, loses most of its liquid water before $h$ reaches $-1000 \mathrm{~cm}$, and the liquid water content of loam gradually decreases both before and after freezing (Fig. 1a). The decreasing rate of decline of liquid water content in the stagnating stage would depend on the shape of the retention curve at $h \approx-1000 \mathrm{~cm}$.

\section{Relationship between unfrozen water content and pressure head}

Figure 4 shows the relationship between the liquid water content, $\theta_{1}$, and the pressure head, $h$, measured simultaneously at each depth. The pressure head represented in 

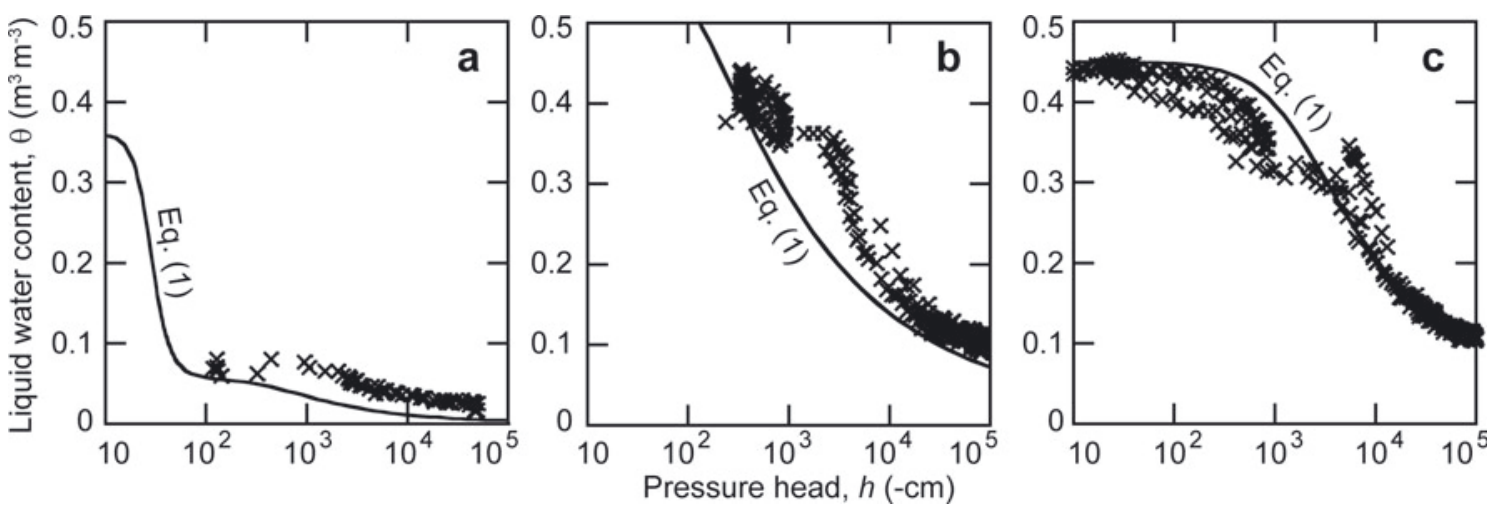

Fig. 4. Relationship between water content and pressure head for three soils during the freezing process: (a) sand, (b) loam and (c) silt loam. The plots are measured by TDR during freezing experiment, and the solid curves are soil-water retention curves shown in Figure $1 \mathrm{a}$.

Figure 4 was measured by the tensiometer at $h>-800 \mathrm{~cm}$ and estimated from the temperature and Equation (2) at temperatures below $-0.5^{\circ} \mathrm{C}$. Note that the solid curves in the figure are the water retention curves measured at room temperature (Fig. 1a). For all soil types and measured depths, the liquid water content decreased with the pressure head. The $h$ estimated from temperature corresponded well to that measured by tensiometer, confirming that both were reasonable methods for determining $h$ near the freezing front. From the unfrozen stage to the early part of the stagnating stage, the measured $\theta_{1}-h$ relationship agreed with the retention curve. However, from the stagnating to the frozen stage, all soils had more actual liquid water than predicted by the retention curve. The observed water content coincided with the retention curve again when the estimated pressure decreased further. The soil water would require a certain length of time to complete phase transition to pore ice when suddenly cooled to subzero temperatures, and the growth shape of the ice surface in soil may differ from the shape of pore ice formed under temperature equilibrium. Therefore, using the combination of the water-retention curve and Equation (2) for the phase equilibrium would underestimate the unfrozen water content of the soils during the freezing process regardless of soil type when the cooling rate (advancing speed of the freezing front) is fast or a large amount of water has to transition to ice.

\section{Temperature and moisture profiles and changes in the amount of ice}

Figure $5 \mathrm{a}-\mathrm{c}$ show the temperature profiles for the three soils for several freezing durations. In the case of silt loam, results for the higher water content (silt loam 1) are shown in Figure 5 for comparison with the same boundary temperature conditions. When temperature control began at both ends of the column, the soil temperature near the ends quickly approached $T_{\mathrm{L}}$ and $T_{\mathrm{H}}$ (Table 2 ). The temperature profile changed more slowly as the freezing time elapsed. In the cases of loam and silt loam, the temperature gradient in the frozen and unfrozen areas became almost linear after 48 hours, but that of frozen sand continued to curve at 72 hours, following the moisture profiles (Fig. 5g-i). At 48 hours, the temperature gradient in the frozen areas of all soils was larger than that of the unfrozen areas, even though the frozen areas had higher thermal conductivity due to the presence of ice and the ice content changes only slightly once the soil is frozen. This may be due to the latent heat released at the freezing front and the increased efficiency of heat transport with water flow to the freezing front.

Figure $5 d-f$ show the pressure-head profiles for the three soils in which the pressure at temperatures below $-0.5^{\circ} \mathrm{C}$ was estimated from the temperature (Fig. $5 \mathrm{a}-\mathrm{C}$ ) and Equation (2). In the case of sand, the pressure changed drastically around $0^{\circ} \mathrm{C}$. The pressure decreased steeply in the frozen sand in accordance with the temperature profile, while it remained almost constant in the unfrozen area. This is a result of the water retention curve of the sand, in which pressure is not sensitive to changes in water content in the unfrozen range (Fig. 1a). The pressure in the silt loam also changed around $0^{\circ} \mathrm{C}$. The pressure in the unfrozen silt loam decreased with time, keeping a small pressure gradient. By contrast, in the case of loam, the pressure gradient changed with time in both the frozen and unfrozen areas. This may be the result of the water retention curve of the loam, which changes gradually across a wide range of pressure head. By contrast, the sand and silt loam have water-retention curves that differ substantially between the frozen $(h<-1000 \mathrm{~cm})$ and unfrozen $(h>-100 \mathrm{~cm})$ areas.

Figure $5 \mathrm{~g}-\mathrm{i}$ show the moisture profiles observed at the same time as temperature and pressure head. The solid and dashed lines indicate the total and unfrozen water content, respectively; subtracting the unfrozen water from the total water content gives the ice content. The unfrozen water in the sand decreased drastically near $0^{\circ} \mathrm{C}$, and was roughly constant in the frozen area. Conversely, the unfrozen water in the frozen silt loam decreased gradually with the temperature profile. The unfrozen water profiles tended to correspond to their freezing curves (Fig. 1b). For all soils, total water increased in the frozen area and decreased in the unfrozen area. In the frozen area, the total water content of the loam increased as the freezing front passed through, and no further increase was observed after freezing. However, the total water content of the sand and silt loam increased continuously after freezing. A water increase in already frozen areas has also been observed in silt (Fukuda and others, 1980) and sandy loam (Mizoguchi and others, 1986), but not in silica powder (Jame and Norum, 1980). The flow of unfrozen water in frozen soil such as loam is inhibited by a decrease in the pressure head before freezing $(h \approx$ $-1000 \mathrm{~cm}$; Fig. 5e), which does not allow movement of the unfrozen water, as expected based on the freezing curve at 0 to $-0.1^{\circ} \mathrm{C}$ (Fig. $1 \mathrm{~b}$ ), and causes low hydraulic conductivity because of the low water content. 

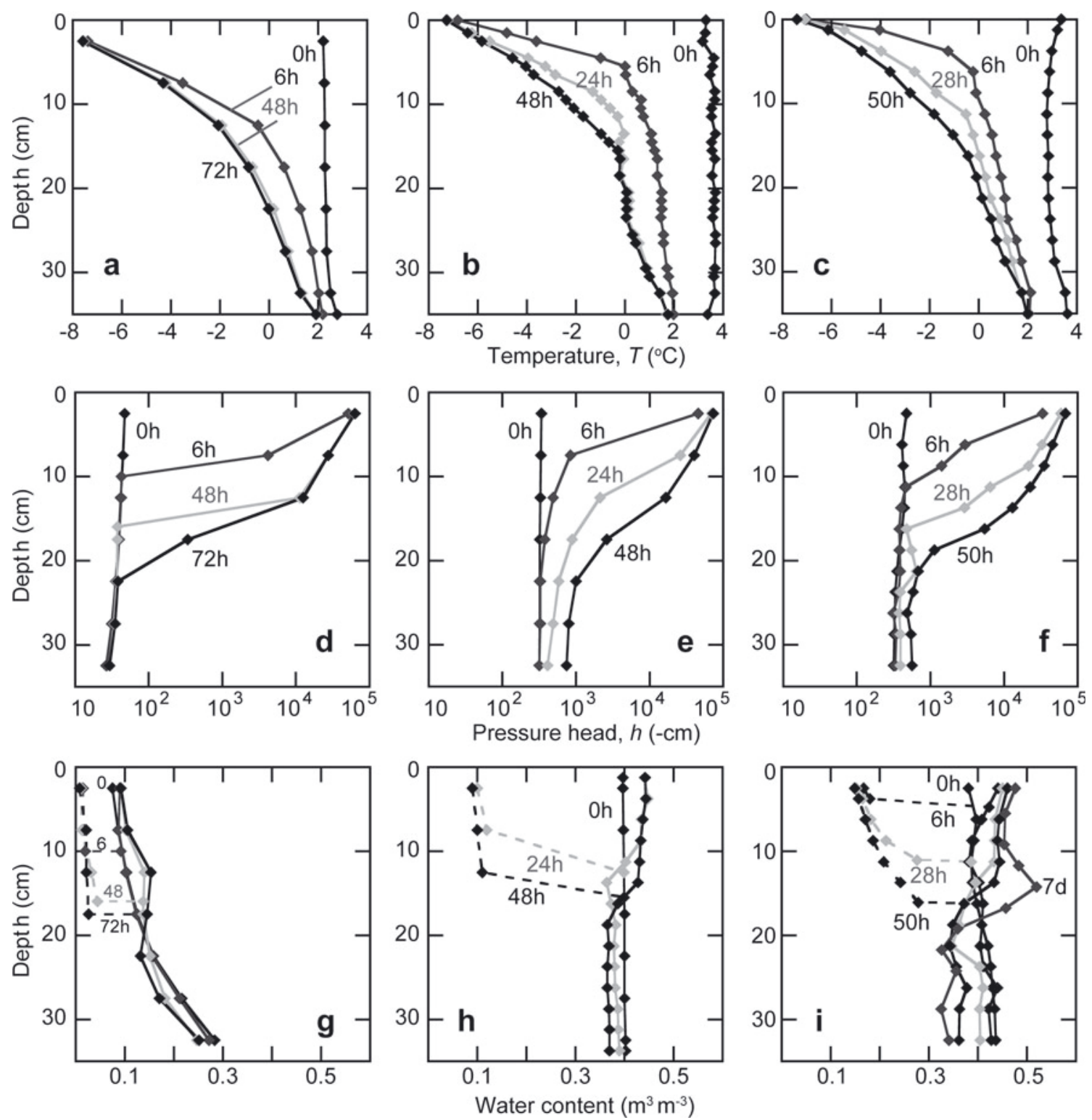

Fig. 5. Temperature $(a-c)$, pressure-head $(d-f)$ and moisture (g-i) profiles of three soils: sand $(a, d$, g), loam (b, e, h) and silt loam (c, f, i). $\mathrm{h}$ following numbers indicates hours. The solid line and dashed lines in moisture profiles (g-i) represent total water and unfrozen water contents, respectively.

As freezing time elapsed (sand: 72 hours; silt loam: 7 days), the total water difference between the frozen and unfrozen areas at the near-freezing front increased. The sand had less unfrozen and total water, resulting in less ice content than the other soils. The frost penetration depth was deeper in sand than in the other soils after 6 hours, but shallower after 48 hours, and depended on the thermal conductivity changes of each soil, which in turn depended on the ice and unfrozen water contents.

\section{SUMMARY}

Column freezing experiments were conducted using unsaturated sand, loam and silt loam columns. When a soil column was frozen from the top, upward water flow from unfrozen to frozen areas was observed in each soil. The amount of water flowing from the unfrozen areas differed among the soil types. In the cases of sand and silt loam, the total water content in the frozen areas increased after the freezing front had passed through, while the water content in the frozen loam changed only near the freezing front. Three stages were found when lowering the soil temperature: unfrozen, stagnating near $0^{\circ} \mathrm{C}$ and frozen. The temperature and duration of the stagnating stage differed among soil types. The changes in liquid water content and pressure head in the freezing process were highly dependent on the soil-water retention curve. The liquid water content decreased drastically in the sand, decreased gradually in the loam and decreased at variable speeds in the silt loam. The relationship between unfrozen water content, $\theta_{\mathrm{l}}$, and pressure head, $h$, observed in the freezing experiment agreed approximately with the soil-water retention curve measured using classical methods. However, near the freezing front $(-300<h<-30000 \mathrm{~cm})$, the freezing soil (non-equilibrium) tended to have more water than indicated by the retention curve. This tendency was more significant at early stages of freezing, when the freezing front advanced more rapidly. Considering this change in the $\theta_{1}-h$ relationship with the 
advancing speed of the freezing front, a more precise numerical calculation would be possible for soil freezing. The liquid water reduction and change in the $\theta_{1}-h$ relationship caused lowered hydraulic conductivity and may also affect the differences in water flow among the soil types. Further investigation is needed to estimate the change in the hydraulic conductivity of freezing soil and its effect on unfrozen water flow.

\section{ACKNOWLEDGEMENTS}

We thank the two anonymous reviewers for providing careful reviews, and the scientific editor, R. Greve, for handling the paper. This research was supported by Grantsin-Aid No. 20589001 from the Ministry of Education, Culture, Sports, Science and Technology of Japan.

\section{REFERENCES}

Baker, J.M. and E.J.A. Spaans. 1997. Mechanics of meltwater movement above and within frozen soil. CRREL Spec. Rep. 97$10,31-36$.

Bittelli, M. M. Flury and K. Roth. 2004. Use of dielectric spectroscopy to estimate ice content in frozen porous media. Water Resour. Res., 40(4), W04212.

Black, P.B. and A.R. Tice. 1989. Comparison of soil freezing and soil water curve data for Windsor sandy loam. Water Resour. Res., 25(10), 2205-2210.

Durner, W. 1994. Hydraulic conductivity estimation for soils with heterogeneous pore structure. Water Resour. Res., 30(2), 211-223.

Fukada, M., A. Ohrun and J.N. Luthin. 1980. Experimental study of coupled heat and moisture transfer in soils during freezing. Cold Reg. Sci. Technol., 3(2-3), 223-232.

Hansson, K., J. Šimének, M. Mizoguchi, L.C. Lundin and M.Th. van Genuchten. 2004. Water flow and heat transport in frozen soil: numerical solution and freeze-thaw applications. Vadose Zone J., 3(2), 693-704.
Jame, Y.W. and D.I. Norum. 1980. Heat and mass transfer in a freezing unsaturated porous medium. Water Resour. Res., 16(4), 811-819.

Koopmans, R.W.R. and R.D. Miller. 1966. Soil freezing and soil water characteristic curves. Soil Sci. Soc. Am., Proc., 30, 680685.

Lopez, B. 2007. Cold scapes. Natl. Geogr. Mag., 212(6), 137-151. Miller, R.D. 1973. Soil freezing in relation to pore water pressure and temperature. In Proceedings of the Second International Conference on Permafrost, 13-28 July 1973, Yakutsk, U.S.S.R. Washington DC, National Academy of Sciences, 344-352.

Mizoguchi, M., M. Nakano and K. Shirai. 1986. Simultaneous change of water content, solute and temperature profiles in a partially frozen unsaturated soil. Trans. Jpn. Soc. Irrigation, Drainage Reclamation Eng., 122, 11-17. [In Japanese.]

Singh, P., J.Q. Wu, D. McCool, S. Dun, C.H. Lin and J.R. Morse. 2009. Winter hydrologic and erosion processes in the U.S. Palouse region: field experimentation and WEPP Simulation. Vadose Zone J., 8(2), 426-436.

Spaans, E.J.A. and J.M. Baker. 1996. The soil freezing characteristic: its measurement and similarity to the soil moisture characteristic. Soil Sci. Soc. Am. J., 60(1), 13-19.

Stähli and Stadler. 1997. Measurement of water and solute dynamics in freezing soil columns with time domain reflectometry. J. Hydrol., 195(1-4), 352-369.

Van Genuchten, M.T. 1980. A closed-form equation for predicting the hydraulic conductivity of unsaturated soils. Soil Sci. Soc. Am. J., 44(5), 892-898.

Watanabe, K. and M. Ito. 2008. In situ observation of the distribution and activity of microorganisms in frozen soil. Cold Reg. Sci. Technol., 54(1), 1-6.

Watanabe, K. and T. Wake. 2008. Hydraulic conductivity in frozen unsaturated soil. In Kane, D.L. and K.M. Hinkel, eds. Proceedings of the 9th International Conference on Permafrost, 29 June3 July 2008, Fairbanks, Alaska. Fairbanks, AK, University of Alaska Press, 1927-1932.

Watanabe, K. and T. Wake. 2009. Measurement of unfrozen water content and relative permittivity of frozen unsaturated soil using NMR and TDR. Cold Reg. Sci. Technol., 59(1), 34-41.

Williams, P. 1964. Unfrozen water content of frozen soil and soil moisture suction. Géotechnique, 14(3), 231-246. 